\title{
SOBRE A POSSIBILIDADE DE UMA TERAPIA PARA A CULTURA
}

\section{Edson Souza Siquara}

\begin{abstract}
RESUMO
No $O$ Mal-Estar da Civilização Freud deixa em aberto uma pergunta sobre a possibilidade de a cultura ser, ela própria, neurótica ${ }^{1}$, e neste sentido, se não seria pertinente um tratamento para a cultura; mas a psicanálise surge para curar o indivíduo, que poderia, então, ser considerado saudável, mas tendo que se adaptar a uma cultura doente. Neste artigo tento identificar em Freud e Schiller a possibilidade de uma terapia para a cultura.
\end{abstract}

PALAVRAS-CHAVE: Mal-Estar. Felicidade. Liberdade.

\begin{abstract}
In Freud's Civilization and Its Discontents he leaves open a question about the possibility that culture itself is neurotic, and in this sense, if a cultural therapy would not be appropriate; but psychoanalysis arises to heal the individual, who could then be considered healthy, but having to adapt to a sick culture. In this article I try to identify in Freud and Schiller the possibilities of a therapy for culture.
\end{abstract}

KEY-WORDS: Discontents. Happiness. Freedom.

\section{Introdução}

Johann Christoph Friedrich von Schiller nasceu em 1759 em Ludwigsburg, 10 anos depois de Goethe (1749 - 1832), formou-se em medicina, exercendo esta profissão por pouco tempo, pois seu coração o forçava a poesia e dramaturgia, área onde hoje é mais conhecido, mas se tornou famoso em sua época como historiador, mas aqui nos interessamos por sua veia filosófica. Entre 1790 e 1796 ele se dedica aos estudos e escritos sobre estética, onde vê no belo a possibilidade de elevar o homem moralmente e, com isso, mudar os rumos da civilização.

Como fundamento de sua filosofia Schiller demonstra que o sentimento de beleza, a emoção que sentimos quando temos a experiência do belo, experiência esta estética, é, na verdade, um sentido de liberdade, mas expressamos e exigimos concordância universal de que o objeto da experiência seja belo. Este sentido de liberdade que temos na experiência estética é universal, todo ser com razão e sensibilidade pode sentir, mas tal experiência não

\footnotetext{
1 "Se a evolução cultural tem tamanha similitude com a do indivíduo e trabalha com os mesmos recursos, não seria justificado o diagnóstico de que muitas culturas - ou épocas culturais, ou possivelmente toda a humanidade - tornaram-se "neuróticas' por influência dos esforços culturais?" (2010, p.119-120)

Perspectivas - Revista do Programa de Pós-Graduação em Filosofia da UFT - n. 1 - 2019
} 
se resume as belas artes, apesar de serem elas o veículo ideal, segundo Schiller, para mostrar ao homem que ele possui algo a mais do que a razão, que quer entender e conquistar a natureza, e a sensibilidade animal, aquela onde desejamos o mundo, a riqueza, a fama e o poder. É este algo a mais, que o entendimento não consegue capturar ou explicar, mas sabemos que existe pois é experenciado, que possibilitará um prazer especial, superior, que não encontramos na arte, mas na filosofia ${ }^{2}$ e nas ações morais.

Nosso objetivo neste artigo não é o de demonstrar como se chega ao belo pela via da liberdade em Schiller nem descrever como esta experiência estética nos conduz a elevação do homem para um status moral e com ela a uma organização social onde seria possível pensarmos em felicidade como um prazer na experiência estética, defesa esta que fazemos em outro local ${ }^{3}$. Nosso objetivo é demonstrar um possível link entre a preocupação de Freud em seu texto O Mal-Estar na Civilização de 1930 com as ideias de Schiller, principalmente tentando mostrar que em Freud, a manutenção de sua visão dualista não o permitiu ver uma saída nos escritos daquele autor que ele mesmo cita nesta obra. Tentamos mostrar, no entanto, que mesmo não capturando de Schiller uma saída pela via da liberdade como experiência estética, ele deixa algumas "marcas" em seu texto que permitiriam uma interpretação onde, tanto pela a via psicanalítica em Freud como a filosófica em Schiller, encontramos a liberdade como uma saída para O Mal-Estar na Civilização.

\section{A questão da liberdade no texto de 1930 de Freud}

Logo no início de $O$ Mal-Estar na Civilização $o^{4}$ Freud nos traz duas perspectivas que apresentam o tom desta obra: o da cultura ${ }^{5}$ que determina as pessoas a buscarem "poder, sucesso e riqueza para si mesmas e admira $(\mathrm{rem})$ aqueles que os têm, subestimando os autênticos valores da vida." (2010, p.14, o itálico é meu) e aquela contida na carta resposta de seu amigo, Romain Rolland, ao seu texto O Futuro de Uma Ilusão $o^{6}$, onde lamenta que

\footnotetext{
${ }^{2}$ Posição defendida por Fichte.

${ }^{3}$ Em uma dissertação de Mestrado a ser defendida em fevereiro de 2019.

${ }^{4}$ Usamos a tradução de Paulo César de Souza que se encontra nas Obras Completas, Volume 18 - Freud: O Mal-Estar na Civilização, Novas Conferências Introdutórias à Psicanálise e Outros Textos; 2010; Companhia das Letras.

${ }^{5} \mathrm{O}$ sentido de cultura aqui está muito ligado a cultura do capital, que apresenta como um dos seus efeitos, o distanciamento das pessoas, a falta de acolhimento e principalmente o que a Teoria do Reconhecimento (ver principalmente Charles Taylor e Axel Honneth) indica como necessidade de respeito nas relações intersubjetivas.

${ }^{6}$ Freud, Obras Completas, Volume 17 - Inibição, Sintoma e Angústia, O Futuro de Uma Ilusão e Outros Textos; 2014; Companhia das Letras

Perspectivas - Revista do Programa de Pós-Graduação em Filosofia da UFT - n. 1 - 2019
} 
Freud não "tivesse apreciado corretamente a fonte da religiosidade.", que seria "um sentimento que ele gostaria de denominar sensação de 'eternidade', um sentimento de algo ilimitado, sem barreiras, como que 'oceânico'.” (ibid.). Se considerarmos que o sentimento 'oceânico' descrito por Rolland é, na verdade, um sentido de liberdade, ou seja, que a experiência da religiosidade permite tanto a perspectiva de um acolhimento quanto a de uma experiência estética de liberdade, talvez fosse possível argumentar que a cultura, que nos determina a buscar sucesso, riqueza e poder, nos afasta do que talvez seja nosso mais autêntico valor, o sentido de liberdade, que seria não apenas o que mais desejamos, mas aquilo que mais nos aproximaria da felicidade.

Como os conceitos de sucesso, riqueza e poder não admitem limite superior, apenas inferior, não temos sequer um parâmetro seguro para sabermos se já obtemos sucesso, riqueza e poder suficientes, mas o pior seria se esta busca não nos tornasse, em nenhuma hipótese, felizes, nos afastando, inclusive, desta meta. Se fosse possível a psicanálise indicar que a busca que a cultura nos determina a fazer estivesse nos impedindo de atingir aquilo que realmente desejamos, a felicidade como sentido de liberdade no mundo real, talvez fosse ela, a psicanálise, a instituição com a maior competência, devido ao seu conhecimento da psiquê humana, para redirecionar a cultura de forma que passássemos a buscar a felicidade pela via da liberdade.

Freud indica que possui dificuldades, ele mesmo, em reconhecer esse sentimento "oceânico" (p.15), mas acredita que seja um "conteúdo ideativo que primeiro se junta associativamente ao sentimento." (ibid.), ou seja, se o conteúdo ideativo fosse de liberdade, este seria então associado ao sentimento que se possui sendo ele externado como "ilimitado", "sem barreiras", "oceânico", no caso da arte como Belo ${ }^{7}$ e no da moral como virtuoso, ou seja, a experiência estética que tanto a religião quanto a arte e a moral podem oferecer, seria, então, o do sentido de liberdade. Freud vê a religião, no Mal-Estar da Civilização, mais como uma empresa que dá ao sujeito um sentido de acolhimento, mas se pudermos incluir o sentido de liberdade como uma experiência na religiosidade, e se nas artes e na convivência entre os humanos estas experiências já não são mais possíveis, isto explicaria a importância da religião, mas, neste caso, no campo da ilusão. No campo da realidade, em uma sociedade que busca exclusivamente riqueza, poder e sucesso, tende-se a isolar mais as pessoas que

\footnotetext{
${ }^{7}$ Como informamos na introdução, não iremos nesta oportunidade defender o sentimento de liberdade com a experiência estética do Belo, teoria desenvolvida por Schiller (1759 - 1805)

Perspectivas - Revista do Programa de Pós-Graduação em Filosofia da UFT - n. 1 - 2019
} 
aproximá-las, o que torna o acolhimento cada vez mais difícil. Podemos então perguntar se conseguiríamos ser felizes pelo 'sentido de liberdade' e se seria este o que mais desejamos em nossas vidas. Precisaríamos, portanto, demonstrar que a maior felicidade que podemos ter é a que nos dá um sentido de liberdade.

Freud vai buscar na relação entre o $\mathrm{Eu}$, o Isso e o mundo externo uma possível explicação deste sentimento "oceânico" 8 . Ele esclarece que enquanto bebês não separamos o Eu do mundo externo, somos um todo (p.18). É com o princípio de prazer e de realidade que começamos a separar o Eu do mundo externo e interno, onde o Eu percebe que há algo que se "prolonga para dentro, sem fronteira nítida, numa entidade psíquica inconsciente a que denominamos Isso.” (p.16) e que o princípio da realidade nos força a separar o Eu do mundo externo. Freud afirma então que "esse primário sentimento do Eu (o de totalidade) foi conservado na vida psíquica de muitos homens" "9 (p.19, o itálico é meu), cujos conteúdos ideativos, "ausência de limites e da ligação com o todo" (ibid.), ou de liberdade, explicam o sentimento "oceânico". Este sentimento "oceânico" é uma memória, uma ideia ligada a um afeto do tempo em que sentíamos que éramos um todo, e que conservamos durante nossa vida como um desejo de voltar a este estado de liberdade, já que a perspectiva de totalidade, de infinitude, seria uma definição de liberdade. Podemos considerar, portanto, que carregamos para toda a vida um desejo fundante de nossa psiquê, o de liberdade.

Freud então, tendo identificado a origem do sentimento "oceânico", aquele ligado a experiência primária de totalidade, se pergunta se a religião teria o direito de sugerir ser este sentimento "a fonte de necessidades religiosas" (p.25). A resposta é negativa, pois para Freud as necessidades religiosas estão relacionadas ao "desamparo infantil e da nostalgia do pai"; e inclui ainda que "Um sentimento pode ser uma fonte de energia apenas quando é ele mesmo expressão de uma forte necessidade." (ibid.), que no caso da religião estaria primariamente identificada com a do acolhimento paterno, expressão do amor deste para a criança. Então, podemos admitir que nossa relação com a religiosidade nos permiti um sentido de acolhimento paterno, mas a religião não deveria, segundo Freud, reclamar para si

\footnotetext{
${ }^{8}$ Schiller em sua $19^{a}$ carta ao Duque de Augustenburg afirma que "O estado do espírito humano antes de qualquer determinação pela impressão dos sentidos é uma determinabilidade sem limites." Mas quando nossos sentidos são afetados, "Há, portanto, realidade, mas a infinitude se perdeu." (1989, p.91). Para Schiller esta experiência na formação de nossa humanidade, o de liberdade anterior a experiência da realidade, carregamos pela vida como nosso maior desejo. A liberdade é o que fundamenta a estética deste poeta/filósofo.

${ }^{9}$ Schiller afirmaria que seria universal esta memória.
}

Perspectivas - Revista do Programa de Pós-Graduação em Filosofia da UFT - n. 1 - 2019 
a experiência de liberdade. Mas mesmo que a religião não tenha tal direito, podemos "nos ater ao fato de que a conservação do passado na vida psíquica é antes a regra do que a surpreendente exceção" (p.24) e que se estivermos dispostos a reconhecer "que em muitos homens há um sentimento 'oceânico', e inclinados a fazê-lo remontar a uma fase primitiva do sentimento do Eu" (p.25), podemos admitir que este sentimento "oceânico", ou de liberdade, possui forte necessidade, mesmo que não ligado a religiosidade. Freud já havia demonstrado ${ }^{10}$ que o acolhimento na religião está no campo da ilusão, então, em termos de fortes necessidades originais, sobra a pergunta se no mundo real poderíamos atender uma destas necessidades com a experiência de liberdade, a alternativa que fica para sermos felizes.

Freud identifica que "o que revela a própria conduta dos homens acerca da finalidade e intenção de sua vida, o que pedem eles da vida e desejam nela alcançar...” é "a felicidade" (p.29). Ele parte então para uma série de análises onde tenta identificar possíveis fontes através das quais poderíamos chegar a felicidade. Sobre a religião ele fala de uma fuga, nas artes e ciências conseguiríamos "gratificações substitutivas" (ibid.); paliativos nas drogas; informa também que temos a necessidade de nos afastar das dores, que o mundo real torna difícil tal empreendimento, mas desejamos ter prazer, sendo este o "sentido mais estrito" (p.30) quando nos referimos a felicidade. Ele inclui também a possibilidade de atingirmos a felicidade no amor, na nossa capacidade de amar e ser amado, mas parece que nada é uma solução válida para todos (p.41). Dado o princípio de realidade, parece que o projeto de felicidade, levando em consideração todas estas possibilidades, tende a ser inexequível (p.30). Nada parece ser uma solução, nem a limitação de nossas pulsões agressivas, nem o deslocamento da libido, nem na fantasia, nada parece ser uma resposta universal. Uma outra possibilidade levantada por Freud é daqueles que veem a realidade como "único inimigo, a fonte de todo o sofrimento, com a qual é impossível viver" e com a qual devemos "romper todos os laços, para ser feliz em algum sentido" (p.37). Temos então esta possibilidade de romper todos os laços com a realidade, como faz o eremita, mas podemos também refazê-la, "construir outro em seu lugar" (ibid.), mas como um projeto individual seria infrutífero.

\footnotetext{
${ }^{10}$ Ver nota 7
}

Perspectivas - Revista do Programa de Pós-Graduação em Filosofia da UFT - n. 1 - 2019 
Na parte III do O Mal-Estar da Civilização Freud fala especificamente do individuo que se torna neurótico por não suportar as privações que a sociedade lhe impõe devido aos seus ideais culturais (p.45), porém, reconhece avanços em diversos aspectos, principalmente aqueles ligados as ciências e a técnica, mesmo que estes fatores parecem não tornar os humanos mais felizes. Neste ponto Freud identifica o que seria a essência da civilização: "a proteção do homem contra a natureza e a regulamentação dos vínculos dos homens entre si." (p.49). Com relação ao primeiro aspecto o progresso é tão significativo que Freud, mesmo antes da Segunda Grande Guerra, identifica o homem como um "Deus", mas esta semelhança tampouco nos faz mais felizes (p.52). Com relação ao segundo aspecto, nosso interesse pessoal pode ser conflitante com o de nosso vizinho, então a cultura deve regular estas relações fazendo com que a maioria possa ser sempre mais forte que qualquer indivíduo, que, segundo Freud, seria o passo cultural decisivo (p.57). Neste sentido o indivíduo cede parte de sua liberdade para permitir o convívio na cultura, mas "ele sempre defenderá sua exigência de liberdade individual contra a vontade do grupo.” (p.58).

É importante aqui separar duas ideias distintas de liberdade: a liberdade individual mencionada por Freud está intrinsicamente relacionada com a história do pensamento onde o contexto é a de interesse pessoal (ser livre é fazer tudo e ter tudo que eu quero) em oposição ao interesse coletivo (que me restringe, ou seja, me limita, me tornando não livre), onde entra a dimensão da justiça; um outro conceito é o de sentido de liberdade, este como uma experiência estética que aqui defendemos como o maior desejo humano e buscamos nele uma causa determinante para a felicidade. Esta diferença fica clara quando ele afirma que “A liberdade individual não é um bem cultural..." (p.57), ou seja, não é um objetivo da cultura. Poderíamos, no entanto, nos sentirmos felizes caso tenhamos sucesso em ligar o sentido de liberdade a felicidade e adicionalmente, buscar a felicidade no equilíbrio ou harmonização ${ }^{11}$ entre as exigências individuais e aquelas da civilização, levando em consideração a necessidade desta de ser construída "sobre a renúncia pulsional" (p.60). Ou seja, em muitos casos, quando priorizamos a sociedade em detrimento de nosso interesse pessoal, agimos moralmente e isto também nos deveria fazer felizes, pois o prazer que sentimos quando agimos ou vemos alguém agir moralmente é de natureza estética. Mas

\footnotetext{
${ }^{11}$ Em um artigo o autor faz uma defesa de uma interpretação sobre este equilíbrio das exigências individuais e da civilização usando a obra de Adam Smith, Teoria dos Sentimentos Morais; ver: https://www.academia.edu/37106363/O_conceito_de_Espectador_Universal_e_Senso_Moral_em_Adam_Sm ith 
como seria possível explicar esta renúncia e mais, como ainda ser feliz tendo que renunciar aos nossos instintos, principalmente aqueles que temos que ceder em prol da civilização?

Freud responde a esta questão no capítulo VII lembrando de nosso desejo de sermos amados por nossos pais e o medo de perder este amor. É a possibilidade da perda deste amor que transferimos ou repetimos para a sociedade, que nos faz sentir culpados quando priorizamos nosso interesse ao dela, ou seja, quando "Se perde o amor do outro, do qual é dependente, deixa também de ser protegido contra perigos diversos" (p.94). No mesmo sentido o Super-Eu faz também o papel da sociedade, monitorando nossos pensamentos e ações, "atormenta o Eu pecador com as mesmas sensações de angústia e fica à espreita de oportunidades para fazê-lo ser punido pelo mundo exterior.” (p.95). O Super-Eu não se contenta apenas com a renúncia a pulsão e o sentimento de culpa a abstenção virtuosa já não é recompensada com a certeza do amor, pois mesmo renunciando, o Super-eu reconhece no Eu o desejo e já o atormenta por isto. Com o Super-eu, a possibilidade é de uma eterna "infelicidade interna, a tensão da consciência de culpa." (p.98). O Super-Eu é, portanto, uma espécie de representante da cultura, sempre presente e atuante em nosso Eu. Como seria então possível uma harmonização entre nossos desejos, nossos interesses pessoais, as demandas da cultura e as do Super-Eu?

Marcuse (1898 - 1979) em sua obra Eros e Civilização" nos lembra que "Schiller derivou da concepção kantiana a noção de um novo modo de civilização.” (1999, p.160) onde buscava uma reconstrução desta "em função da força libertadora da função estética, sendo que esta função foi considerada como contendo a possibilidade de um novo princípio de realidade." (p.162). Esta força libertadora que está na ordem da sensualidade contra a ordem da razão de herança iluminista e da ciência, "almeja uma libertação dos sentidos que, longe de destruir a civilização, dar-lhe-ia uma base mais firme e incentivaria muito as suas potencialidades." (p.163). A estética de Schiller, portanto, na busca de atender o maior desejo humano, o do sentido de liberdade, traria junto a abolição da "compulsão e colocaria o homem, moral e fisicamente, em liberdade" (ibid.). Harmonizaria, assim, os sentimentos e afeições com as ideias da razão, que segundo Schiller privaria as "leis da razão de sua compulsão moral" e, simultaneamente, "reconciliá-las-ia com o interesse dos sentidos" (ibid., apud SCHILLER, 1845, pg. 66-67). Marcuse vê então na concepção de Schiller um

\footnotetext{
${ }^{12}$ Uma interpretação filosófica do pensamento de Freud, 1999

Perspectivas - Revista do Programa de Pós-Graduação em Filosofia da UFT - n. 1 - 2019
} 
diagnóstico da doença da civilização como sendo "um conflito entre os dois impulsos básicos do homem, os impulsos sensuais e formais" (p.169), este representante da cultura, apresentando, então, como solução uma reconciliação destes impulsos restringindo a tirania repressiva da razão sobre a sensualidade.

\section{Conclusão}

Schiller denomina de bárbara uma cultura cujos princípios destroem seus sentimentos, mas selvagem aquela onde os sentimentos imperam sobre os princípios. A cultura moderna nos coloca na barbárie, violentados pela busca racional de riqueza, poder e fama, nos afastando do nosso maior desejo e destino, a liberdade para sermos felizes. Não desejamos ser bárbaros, mas tampouco selvagens. Neste sentido Schiller advoga que ambos os impulsos que caracterizam o humano, razão e sensibilidade, precisam ser desenvolvidos; para o primeiro, onde Freud sintetizou como "a proteção do homem contra a natureza", reconhecemos que este desenvolvimento está garantido, mas para o segundo que serve como base para a "regulamentação dos vínculos dos homens entre si”, só há opressão e o homem com isto passa a vida a sofrer. Schiller defende, portanto, uma Educação Estética, onde desenvolveríamos a nossa sensibilidade, o que nos diferenciaria da sensibilidade do selvagem, por ser aquela treinada pelas Belas Artes, pela apreciação do Belo, desenvolvendo uma sensibilidade que poderíamos denominar de "fina". Assim,

Cada um destes dois impulsos fundamentais, tão logo se tenha desenvolvido, empenhase, natural e necessariamente, por sua satisfação, e justamente porque ambos se esforçam necessariamente por objetos opostos, este duplo constrangimento suprime-se reciprocamente, e a vontade afirma uma perfeita liberdade entre ambos. (1989, p.93).

Esta experiência de liberdade, como aquela original que tínhamos quando éramos uma totalidade e que nos marca para toda a vida, aquela que a religião afirma oferecer como um "sentimento oceânico", a mesma que temos como experiência estética com as Belas Artes, aquela que nos torna um ser moral sem que nos sintamos violentados em nossos desejos, é a que seria, portanto, a cura para a doença da civilização, pois deixaríamos de buscar riqueza, poder e sucesso, e nos voltaríamos para encontrar a experiência de liberdade em todas as nossas relações, principalmente aquelas que temos no convívio na cultura. 


\section{AGRADECIMENTOS}

O autor agradece a revisão cuidadosa dos colegas Kátia Leite de Carvalho, Otacílio José Moreira Ribeiro e Messias Eustáquio Chaves.

\section{REFERÊNCIAS BIBLIOGRÁFICAS}

FREUD, Sigmund; O Mal-Estar na Civilização, Novas Conferências Introdutórias à Psicanálise e Outros Textos. Obras Completas Volume 18. Trad. Paulo César de Souza; Companhia das Letras, 2010

MARCUSE, Herbert; Eros e Civilização: Uma Interpretação Filosófica do Pensamento de Freud. Trad. Álvaro Cabral; Ed. Guanabara Koogan; 1999; $8^{a}$ ed.

SCHILLER, Friedrich. A Educação Estética do Homem. Trad. Roberto Schwarz e Márcio Suzuki; Ed. Iluminuras, 1989 